\title{
Editorial
}

\section{LA IMPORTANCIA DE LA SALUD BUCAL EN EL CONTEXTO LATINO AMERI- CANO.}

En el año 2011, la Organización de Naciones Unidas, realizó una reunión de alto nivel, sobre prevención y control de las enfermedades no transmisibles ${ }^{1}$,llevada a cabo en Nueva York entre el 19 y 20 de septiembre. En esta reunión los jefes de estado y de gobierno aprueban una declaración política sobre la prevención y control de las enfermedades no transmisibles en todo el mundo, preocupándose particularmente en los problemas de desarrollo y en sus consecuencias sociales y económicas, principalmente para los países que ellos denominan en desarrollo. La declaración empieza con el reconocimiento de la carga de enfermedad que generan las enfermedades no transmisibles, puntualizan también que es responsabilidad de los gobiernos,responder a este reto y que es de urgente necesidad intensificar las medidas para su prevención y control. En cuanto a salud bucal menciona en el artículo 19 "Reconocemos que las enfermedades renales, bucodentales y oculares constituyen una carga importante para el sector de la salud de muchos paises, y que estas enfermedades comparten factores de riesgo y pueden beneficiarse de las respuestas comunes a las enfermedades no transmisibles" 2 .

La mayor parte de sistemas de salud, categorizan a la caries dental dentro de las enfermedades no transmisibles. Existen muy pocas investigaciones poblacionales que nos permitan conocer el estado actual de la prevalencia de caries, enfermedad periodontal, mal oclusiones y cáncer bucal, tal vez por la dificultad de hacer un estudio descriptivo a nivel nacional o por el costo que implica, sin embargo existen esfuerzos puntuales, parciales, locales realizados fundamentalmente por las universidades, que periódicamente van realizando levantamientos epidemiológicos. Tanto en la disciplina de gestión como en la de gerencia en salud se considera como un dogma, que las acciones que no se miden no se pueden gestionar, de ahí deviene la importancia de los estudios epidemiológicos.

La carrera de Odontología de la Universidad Católica de Cuenca, en el año 2015 ha elaborado un macro estudio sobre calidad de vida relacionada a la salud bucal en escolares de 11 y 12 años de edad, utilizando el instrumento de calidad de vida relacionada a la salud bucal ChildOIDP, esta investigación se ejecutó mediante la elaboración de múltiples estudios en escuelas de

\footnotetext{
${ }^{1}$ Organización de Naciones Unidas ONU. Declaración Política de la Reunión de Alto Nivel de la Asamblea General sobre la Prevención y el Control de las Enfermedades No Transmisibles. En Seguimiento de los resultados de la Cumbre del Milenio; 2011; Nueva York. p. 14.

${ }^{2}$ Idem.
} 
la ciudad y en el año 2016 ha realizado un segundo estudio epidemiológico de salud bucal en la ciudad de Cuenca, en la misma modalidad, midiendo índice de caries, enfermedad periodontal, índice de higiene oral, prevalencia de maloclusiones, autopercepción de estas mismas condiciones y algunos hábitos de higiene bucal, con el propósito de incrementar la evidencia científica de estas variables para una mejor planificación de la oferta académica de pre grado y posgrado.

En este volumen 2 de la revista, correspondiente al año 2017, se publicarán algunas de estas investigaciones, con la finalidad de contribuir a la producción de evidencia científica básica en el Ecuador y como contribución de la carrera de Odontología a la vigilancia epidemiológica de la salud bucal, esperando poder compartir estos resultados con pares académicos latinoamericanos, a fin de generar y consolidar un observatorio epidemiológico regional, constantemente actualizado integrando a las Universidades en la discusión del estado de salud bucal de nuestras naciones y en el planteamiento de políticas, programas y proyectos para la mejora de la salud bucal que repercutirá en la calidad de vida de nuestros pueblos.

Dr. Ebingen Villavicencio Caparó Director de la Revista 